Article

\title{
Evaluation of Airport Sustainability by the Synthetic Evaluation Method: A Case Study of Guangzhou Baiyun International Airport, China, from 2008 to 2017
}

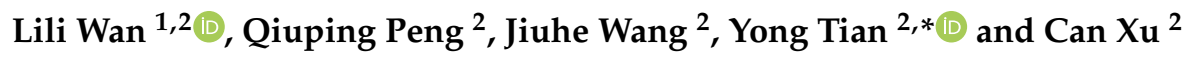 \\ 1 College of Economics and Management, Nanjing University of Aeronautics and Astronautics, \\ Nanjing 210016, China; wanlili@nuaa.edu.cn \\ 2 College of Civil Aviation, Nanjing University of Aeronautics and Astronautics, Nanjing 210016, China; \\ peng970511@nuaa.edu.cn (Q.P.); wjh1396@nuaa.edu.cn (J.W.); xucan@nuaa.edu.cn (C.X.) \\ * Correspondence: tianyong@nuaa.edu.cn
}

Received: 27 March 2020; Accepted: 16 April 2020; Published: 20 April 2020

\begin{abstract}
Although the concept of sustainable development has made certain achievements in many fields, airport sustainability (AS) has not yet formed a unified and comprehensive theory and evaluation method. According to the connotation of sustainable development, this paper proposes the definition of airport sustainability by considering China's national conditions and airport characteristics. Secondly, this paper identifies four AS dimensions of economy, environment, society, and operation and selects and screens evaluation indicators for each dimension. Thirdly, a synthetic evaluation index model of AS is constructed based on the benefit of the doubt (BoD) model, and the process of evaluation method is planned according to a synthetic evaluation method. Finally, Guangzhou Baiyun International Airport (CAN) is selected as a case study to evaluate the AS from 2008 to 2017, and the influencing factors of AS are discussed to predict AS in 2018. The evaluation and prediction results are consistent with the actual operational characteristics of CAN.
\end{abstract}

Keywords: airport sustainability; dimensions; synthetic evaluation index; BoD model

\section{Introduction}

In order to ensure rapid and healthy socioeconomic development, the concept of sustainability came into being [1]. Today, convenient and flexible transportation has greatly promoted the rapid development of the global economy and society, but at the same time, the increase in traffic has also negatively affected sustainability. As the fastest growing industry in transportation [2], the average annual growth rate of aviation is $5 \%$. While promoting economic development and solving social employment issues [3], aviation has also caused huge environmental impacts [4]. As a key point and infrastructure of aviation, airports not only play a role in connecting ground traffic and air traffic [5] but also serve as interactive hubs for airlines, air traffic service providers, and passengers [6]. The sustainability of airports and aviation are complementary to each other. Therefore, while continuously exploring aviation development, airports should also enhance their sustainability to meet the development demand of the industry.

At present, implementation activities have been widely carried out worldwide to promote airport sustainability. Federal Aviation Administration (FAA) proposed the noise compatibility program and voluntary airport low emissions program and established the airport improvement program to reduce their environmental impact by providing some airports with renovation funds [7]. In 2016, nearly 20 airports signed the "Airports Sustainability Declaration" at the Airports Going Green Conference (AGGC) [8]. In addition, some airports have begun to explore their own sustainable 
development. San Francisco International Airport (SFO) adopted the economic viability, operational efficiency, natural resource conservation, and social responsibility (EONS) guidelines of Airports Council International (ACI) to develop its sustainability plans and practices and made a five-year plan in 2017 [9]. Sea-Tac Airport released the Sustainable Airport Master Plan (SAM) [10]. Heathrow Airport invested 500,000 pounds to reduce environmental impacts such as aviation noise and carbon emissions [11]. Groningen Airport in the Netherlands launched the Green Sustainable Airport (GSA) Program in Europe in 2010, which aims to improve the airport environment and promote sustainable development of aviation by reducing greenhouse gases, emissions, and noise [12]. The Kansai airport group has formulated a sustainable development strategy from four aspects, climate change, resource utilization, environmental harmony, and management, to mitigate the environmental impact of the airport [13]. Hong Kong international airport has also formulated a sustainable development policy and assessed airport sustainability by involving all the participants in aspects of airport operations as stakeholders [14]. Therefore, it can be seen that global airports have begun to implement sustainable development projects in response to the increasing environmental impact of aviation.

In the exploration of sustainability, technological innovation was considered as the primary plan for achieving sustainable development [15], and current research mostly focuses on reducing the environmental impact of airports. However, with the increase of air traffic, technological innovation cannot solve a series of problems brought by aviation [16]. We need to address sustainability from a management perspective. The assessment of sustainability is a prerequisite for effective management [17]. Only based on the correct evaluation can airport sustainability be guaranteed and improved by taking targeted measures. The evaluation criteria and methods have a key role and significance for sustainability [18]. Therefore, in order to achieve sustainability of airports and aviation, it is necessary to construct scientific evaluation criteria and methods of airport sustainability.

The evaluation of airport sustainability is a special issue of integrating theory with practice. It is necessary to clarify the existing practical operational problems of airports and understand the relationship between the theory and practice. Some scholars discuss airport sustainability from a certain aspect of daily operation and give some suggestions on practical operation, such as airport energy management [19], water resource utilization [20], airport pavement materials [21], and the development of commercial aspects of airports [22], and so on. Although these studies are easy to carry out, they lack structure and integrity. However, there are relatively few assessment studies specifically for airport sustainability, and some related studies include the following. Milan Janic involved the airport when assessing the sustainability of the air transport system [23]. Vincenzo Fasone pointed out two goals in airport system management; one is the airport's financial sustainability, and the other is that infrastructure investment and maintenance of the airport can meet the transportation needs [24]. Kılk1s used the Sustainability Ranking of Airports (SRA) Index to evaluate airport sustainability, including five dimensions and 25 evaluation indicators [25]. Postorino et al. proposed a common framework from the four dimensions of economy, society, environment, and operation to reduce the environmental impact of airports and promote aviation sustainability [26]. Ming-Tsang Lu established an evaluation method of airport sustainability with a balanced scorecard model [27]. Monsalud quantified airport sustainability with the impact matrices and analyzed effective sustainability practices at U.S. airports [28]. Laya Olfata used a fuzzy dynamic network to evaluate the operational efficiency of airport systems and determine the level of sustainability [29]. The United Kingdom Airport Commission proposed an evaluation framework based on Multi-Criteria Analysis (MCA) in 2014 to assess the environmental and social impacts of airports [30]. The current related research mainly focused on the development of aviation, airport operational practices, airport development decisions, and airport green development. There are not many studies on airport sustainability, and the comprehensive assessment of airport sustainability generally adopts the methods of constructing indicator systems and models. Airport sustainability (AS) is not a constant value, and it changes with socioeconomic development. We should pay attention to its dynamic changes to explore the development potential of airports. On the basis of existing research achievements, this paper takes into account an airport's operational needs in the definition of airport 
sustainability by combining the development characteristics of the airport and uses comprehensive indicators to evaluate AS dynamically. This method can enrich the evaluation content and methods of airport sustainability and provide more possibilities for AS's extended research, such as prediction and improvement.

In order to evaluate airport sustainability more scientifically, this paper gives the definition of airport sustainability based on the connotation of sustainable development and airport operational characteristics. It adopts a combination of indicator system and comprehensive index and uses the flexibility and optimism of the benefit of the doubt $(\mathrm{BoD})$ model to reflect the changing process of airport sustainability. The evaluation process can fully reflect the relationship between the practice and theory of the airport. This paper is organized as follows: Section 2 gives the definition, dimensions, and evaluation framework of airport sustainability. Section 3 proposes the evaluation method of the synthetic airport sustainability index based on the BoD model, including index model, weight calculation, and indicator processing. The results and discussions of the Guangzhou Baiyun International Airport (CAN) case study are analyzed in Section 4, and Section 5 is the conclusion.

\section{Definition and Evaluation Framework}

\subsection{Airport Sustainability (AS)}

The current accepted definition of sustainability is the ability to meet the needs of contemporary human development without compromising the future generations [1].

At present, there is no unified definition of airport sustainability, but some institutions have conducted relevant research: The Airport Cooperative Research Program (ACRP) proposed that AS should be "practices that ensure: protection of the environment, including conservation of natural resources" [31]. Airports Council International, North America's airport sustainability committee, considered airport sustainability as "a holistic approach to managing an airport so as to ensure the integrity of the economic viability, operational efficiency, natural resource conservation and social responsibility of the airport" [32]. FAA stated that airport sustainability should include reducing environmental impact, ensuring rapid and stable economic development and promoting social progress [33]. ACI proposed that aviation and airport sustainability could be promoted by mitigating environmental impacts and improving economic and social benefits [34]. The Sustainable Aviation Guidance Alliance (SAGA) recommended that airports should define their own definitions of airport sustainability based on their characteristics [35].

Although the definitions of AS are different, it will continue to change with the social environment. The Civil Aviation Administration of China (CAAC) also proposed that a green airport refers to an airport's ability to achieve resource conservation, environmental friendliness and airworthiness, humane service, orderly development on demand, and coordinated development with surrounding areas throughout its entire life cycle. [36]. In order to meet the requirements of sustainability strategies with Chinese characteristics, the core of AS is to control the environmental impact, ensure economic and social benefits, and focus on improving operational efficiency. In summary, this paper defines airport sustainability (AS) as: "First, we should protect the environment and control the impact of airport development on the surrounding residents. Second, we should achieve stable economic growth while ensuring the airport's service quality and operational efficiency and fulfilling social responsibilities."

\subsection{Dimensions}

Sustainable development usually includes the three dimensions of economy, environment, and society [37]. Bartle proposed sustainable transportation development including financial, economic, environmental, and social dimensions [38]. Rebecca K stated that these four dimensions are applicable to aviation sustainability [39]. The financial dimension in the literature refers to the generation of sufficient funds to cover capital and operating costs in the long run. For an airport, it means that the airport can guarantee the balance of payments in terms of economic operations. This dimension 
is usually the theoretical economic dimension. The economic dimension in the literature refers to achieving the highest social return on physical and natural capital. For an airport, it means the operating efficiency of airport. International Air Transport Association (IATA) also pointed out that improving airport efficiency is an important means to promote the sustainable development of aviation, and they released the ninth edition of the "Worldwide Slot Guidelines" in 2019 [40]. This dimension actually describes the operating characteristics of an airport, and it can be called the operational dimension. The environmental dimension refers to the integration of environmental concerns into transportation. The social dimension refers to improving standard of living, quality of life, and reducing poverty. Therefore, this paper divides the dimensions of AS into four aspects: economy, environment, society, and operation.

\subsection{Evaluation Framework}

In order to fully reflect the dynamic characteristics of airport development and describe AS reasonably and accurately, this paper adopts the comprehensive index evaluation method to evaluate AS. The following are the steps taken in this paper to evaluate airport sustainability:

1. Focus on the research target-definition and dimensions of airport sustainability.

2. Select and calculate the evaluation indicators-choose the corresponding evaluation indicators from four dimensions.

3. Screening indicators-filter indicators based on relevance and independence.

4. Optimize indicator and index weights—calculate the weights of indicators and indexes based on the BoD model.

5. Evaluate AS-construct a synthetic evaluation index model to evaluate airport sustainability.

6. Analyze and predict AS-analyze the factors affecting airport sustainability and establish a regression function to predict AS.

The main process of the framework in this paper is illustrated in Figure 1.

\begin{tabular}{|c|c|c|c|}
\hline $\begin{array}{c}\text { Airport } \\
\text { Sustainbility }\end{array}$ & $\begin{array}{l}\text { Indicators } \\
\text { processing }\end{array}$ & Assessment & $\begin{array}{l}\text { Analysis and } \\
\text { Prediction }\end{array}$ \\
\hline $\begin{array}{l}\text { - Definition } \\
\text { - Dimensions }\end{array}$ & $\begin{array}{l}\text { - Selection } \\
\text { - Normalization } \\
\text { - Screening }\end{array}$ & $\begin{array}{l}\text { - BoD model } \\
\text { - Synthetic Index }\end{array}$ & $\begin{array}{l}\text { - Impact factor } \\
\text { - Regression }\end{array}$ \\
\hline
\end{tabular}

Figure 1. Evaluation framework of airport sustainability (AS).

\section{Synthetic Evaluation Method}

\subsection{Synthetic Evaluation Index}

The synthetic evaluation index integrates multiple individual evaluation indicators into a general index to perform a comprehensive and objective evaluation of the evaluation objects. Because AS is a complex, dynamic, and systematic issue, it has multi-standard, multi-dimensional, and difficult-to-measure characteristics. Therefore, this paper adopts the airport sustainability index (ASI) as a synthetic evaluation index.

The synthetic evaluation index is obtained through combination of indicators and weights, usually using multiple criteria decision analysis (MCDA). The method of MCDA mainly includes simple additive weight (SAW), weighted geometric mean (WGM), weighted product (WP), etc. Among them, the weighted product (WP) method is a method in which the system with poor performance in some attributes is penalized more heavily. Zhou [41] found that the WP method is superior to the other two methods in constructing the synthetic evaluation index because in most cases it results in the minimum loss of information. Therefore, this paper adopts the WP method to build the ASI according 
to the combination of the economic, environmental, social, and operational airport sustainability index. The $i$-th sample of ASI $\left(A S I_{i}\right)$ can be expressed as:

$$
\begin{gathered}
A S I_{i}=\prod_{j}\left(S I_{i j} / g_{j}(d)\right)^{\xi_{i j}} \\
S I_{i j}=\prod_{k}\left(y_{i j k}^{B}\right)^{\omega_{i j k}} \\
y_{i j k}^{B}= \begin{cases}y_{i j k} / g_{k}(d) & \text { positive indicator } \\
g_{k}(1-d) / y_{i j k} & \text { negative indicato }\end{cases}
\end{gathered}
$$

where $S I_{i j}$ is the index of the $j$-th dimension in the $i$-th sample; $g_{i}(d)$ is the $d$-th percentile of the $j$-th dimension index value; $\xi_{i j}$ is the weight of the $j$-th dimension in the $i$-th sample; $\omega_{i j k}$ is the weight of the $k$-th indicator of the $j$-th dimension in the $i$-th sample; $y_{i j k}$ is the $k$-th indicator value of the $j$-th dimension in the $i$-th sample; and $g_{k}(d)$ is the $\mathrm{d}$-th percentile of the $k$-th indicator value.

\subsection{Indicator Processing}

\subsubsection{Selection}

Some scholars put forward related evaluation indicators about airport operation and green development. Table 1 lists the evaluation indicator sets related to AS. These related evaluation indicator sets propose different scales of sustainability indicators from the economic, environmental, operational, or multi-dimensional dimensions.

Table 1. Sets of related evaluation indicators.

\begin{tabular}{cccccc}
\hline No & Indicator set & Authors & $\begin{array}{c}\text { Number of } \\
\text { Indicators }\end{array}$ & Dimension & Scale \\
\hline 1 & Sustainability Reporting & Global Report & 70 & Multiple & global \\
2 & $\begin{array}{c}\text { Guidelines } \\
\text { GrADE framework }\end{array}$ & $\begin{array}{c}\text { Initiative [42] } \\
\text { Paolina Ferrulli [43] }\end{array}$ & 22 & Environment & local \\
3 & $\begin{array}{c}\text { Airport sustainability } \\
\text { ranking index }\end{array}$ & Şan Kılkış [25] & 25 & Multiple & global \\
4 & $\begin{array}{c}\text { Indicator systems of } \\
\text { sustainability }\end{array}$ & Milan Janic [23] & 12 & Multiple & regional \\
5 & $\begin{array}{c}\text { Airport sustainability } \\
\text { indicators }\end{array}$ & Setiawan M. I. [22] & 8 & Operation & global \\
6 & $\begin{array}{c}\text { Perspectives/criteria of } \\
\text { airport sustainability }\end{array}$ & Ming-Tsang Lu [27] & 15 & Multiple & regional \\
7 & $\begin{array}{c}\text { Airport impact analysis } \\
\text { framework }\end{array}$ & Linna Li [44] & 17 & Multiple & local \\
8 & $\begin{array}{c}\text { Green airport evaluation } \\
\text { index system }\end{array}$ & Cheng Lun [45] & 28 & Economic & local \\
\hline
\end{tabular}

Referring to Postorino's research on the connotation of the four dimensions, this paper removes duplicated indicators from the existing evaluation indicators and obtains 54 evaluation indicators. The results of the extracted indicators are shown in Table 2. The code, name, and direction (positive + /negative -) of the indexes and the indicators are given in the table. 
Table 2. Evaluation indicators of AS.

\begin{tabular}{|c|c|c|c|c|c|c|}
\hline Dimension & & Indicators & $\mathbf{P} / \mathbf{N}$ & & Indicators & $\mathbf{P} / \mathbf{N}$ \\
\hline \multirow{11}{*}{$\begin{array}{l}\text { Economic } \\
\text { (B1) }\end{array}$} & $\mathrm{C} 1$ & Aeronautical revenues (RMB) & + & $\mathrm{C} 12$ & Labor cost (RMB) & - \\
\hline & $\mathrm{C} 2$ & $\begin{array}{c}\text { Non-aeronautical income } \\
\text { (RMB) }\end{array}$ & + & $\mathrm{C} 13$ & Depreciation fee (RMB) & - \\
\hline & $\mathrm{C} 3$ & $\operatorname{ROE}(\%)$ & + & $\mathrm{C} 14$ & Direct cost (RMB) & - \\
\hline & $\mathrm{C} 4$ & ROA (\%) & + & $\mathrm{C} 15$ & Maintenance cost (RMB) & - \\
\hline & $\mathrm{C} 5$ & $\mathrm{ROE} / \mathrm{ROA}$ & + & $\mathrm{C} 16$ & Service charge (RMB) & - \\
\hline & C6 & Profit before tax (\%) & + & $\mathrm{C} 17$ & Other operating costs (RMB) & - \\
\hline & $\mathrm{C} 7$ & Receivable turnover & + & $\mathrm{C} 18$ & $\begin{array}{l}\text { Energy consumption } \\
\text { cost }(\mathrm{RMB})\end{array}$ & - \\
\hline & $\mathrm{C} 8$ & Inventory turnover & + & C19 & Selling expenses (RMB) & - \\
\hline & C9 & Current assets turnover & + & $\mathrm{C} 20$ & Management cost (RMB) & - \\
\hline & $\mathrm{C} 10$ & Fixed assets turnover & + & $\mathrm{C} 21$ & Finance cost $(\mathrm{RMB})$ & - \\
\hline & $\mathrm{C} 11$ & Total assets turnover & & & & \\
\hline \multirow{6}{*}{$\begin{array}{l}\text { Environmental } \\
\text { (B2) }\end{array}$} & $\mathrm{C} 22$ & $\begin{array}{l}\text { Annual mean concentration } \\
\text { distribution of } \mathrm{CO}\end{array}$ & - & $\mathrm{C} 28$ & Sewage discharge $(t)$ & - \\
\hline & $\mathrm{C} 23$ & $\begin{array}{l}\text { Annual mean concentration } \\
\text { distribution of NOx }\end{array}$ & - & $\mathrm{C} 29$ & Water use efficiency & + \\
\hline & $\mathrm{C} 24$ & $\begin{array}{c}\text { Annual mean concentration } \\
\text { distribution of PM }\end{array}$ & - & $\mathrm{C} 30$ & Solid waste (t) & - \\
\hline & $\mathrm{C} 25$ & $\begin{array}{c}\text { Annual mean concentration } \\
\text { distribution of SOx }\end{array}$ & - & $\mathrm{C} 31$ & Greenland rate & + \\
\hline & $\mathrm{C} 26$ & Carbon emissions ( $\mathrm{t}$ ) & - & $\mathrm{C} 32$ & $\begin{array}{l}\text { Land consumption } \\
\text { (ha/10,000 people) }\end{array}$ & + \\
\hline & $\mathrm{C} 27$ & Noise & - & & & \\
\hline \multirow{3}{*}{$\begin{array}{l}\text { Social } \\
\text { (B3) }\end{array}$} & $\mathrm{C} 33$ & Direct economic benefits (RMB) & + & $\mathrm{C} 36$ & Per capita (RMB) & + \\
\hline & $\mathrm{C} 34$ & $\begin{array}{c}\text { Indirect economic } \\
\text { benefits (RMB) }\end{array}$ & + & $\mathrm{C} 37$ & Service satisfaction & + \\
\hline & $\mathrm{C} 35$ & $\begin{array}{l}\text { Airport employment } \\
\text { amount (persons) }\end{array}$ & + & $\mathrm{C} 38$ & Complaints rate (times/year) & - \\
\hline \multirow{9}{*}{$\begin{array}{c}\text { Operational } \\
\text { (B4) }\end{array}$} & C39 & $\begin{array}{l}\text { Daily average traffic volume } \\
\text { (flights/day) }\end{array}$ & + & $\mathrm{C} 48$ & Average check wait time (min) & - \\
\hline & $\mathrm{C} 40$ & $\begin{array}{l}\text { Daily peak traffic volume } \\
\text { (flights/hour) }\end{array}$ & + & $\mathrm{C} 49$ & Average taxiing time (min) & - \\
\hline & $\mathrm{C} 41$ & $\begin{array}{l}\text { Hourly peak traffic volume } \\
\text { (flights/hour) }\end{array}$ & + & $\mathrm{C} 50$ & Capacity utilization & + \\
\hline & $\mathrm{C} 42$ & Hourly capacity (flights/hour) & + & C51 & Weather delays ratio & - \\
\hline & C43 & Release normal rate & + & C52 & Company delays ratio & - \\
\hline & $\mathrm{C} 44$ & Freight throughput (t) & + & C53 & Flow control delay ratio & - \\
\hline & $\mathrm{C} 45$ & $\begin{array}{c}\text { Passenger } \\
\text { throughput (persons) }\end{array}$ & + & C54 & Other airspace users ratio & - \\
\hline & C46 & Average flight delay (min) & - & C55 & Special delays ratio & - \\
\hline & C47 & Average arrival delay (min) & - & & & \\
\hline
\end{tabular}

\subsubsection{Normalization}

Because the units and magnitudes of the various evaluation indicators are different, the inconsistency of the indicator dimensions can be eliminated through normalization. Suppose $x_{i j k}$ is the $j$-th nominal indicator value of the $k$-th dimension in the $i$-th sample and $y_{i j k}$ is the $j$-th original indicator value of the $k$-th dimension in the $i$-th sample. If the indicator is a positive indicator, its normalized formula is as follows:

$$
x_{i j k}=\frac{y_{i j k}-\min _{1 \leq i \leq n}\left(y_{i j k}\right)}{\max _{1 \leq i \leq n}\left(y_{i j k}\right)-\min _{1 \leq i \leq n}\left(y_{i j k}\right)}
$$

If it is a negative indicator, the normalized formula is:

$$
x_{i j k}=\frac{\max _{1 \leq i \leq n}\left(y_{i j k}\right)-y_{i j k}}{\max _{1 \leq i \leq n}\left(y_{i j k}\right)-\min _{1 \leq i \leq n}\left(y_{i j k}\right)}
$$




\subsubsection{Screening}

Because the evaluation indicators are selected from different works in the literature, the selection of the indicators is subjective, and the independence of the indicators is not considered at the same time. Therefore, in order to ensure the independence and representativeness of the indicators, this paper uses a three-step method to screen the indicators:

Step 1: Screening independent indicators by the Spearman and Kendall method.

Step 2: Screening representativeness indicators by methods such as conditional generalized variance minimization (CGVM), principal component analysis (PCA), and fuzzy cluster factor analysis (FCFA).

Step 3: According to the characteristics of the raw data, a non-parametric Bayesian model was used to compare and analyze the discrimination accuracy of the screening results to determine the best screening method.

The non-parametric Bayesian discriminant function is as follows:

$$
P\left(G_{i j} \mid x\right)=\frac{\sum_{i}^{n_{i j}} f_{i j}(x)}{\sum_{i} \sum_{i j} n_{i j} f_{i j}(x)}
$$

where $n_{i j} / \sum_{i} n_{i j}$ refers to the prior probability of a random sample of the $i$-th sample in the $j$-th dimension. $n_{i j}$ refers to the total indicator number of the $i$-th sample in the $j$-th dimension, $f_{i j}(x)$ refers to the kernel density function of the $i$-th sample in the $j$-th dimension, $P\left(G_{i j} \mid x\right)$ refers to the posterior probability of the random sample of the $i$-th sample in the $j$-th dimension.

Following the above steps, the indicator selection process is more flexible, and different screening methods can be selected according to the indicator characteristics in different AS dimensions.

\subsection{BoD Weighting}

This paper calculates the index and indicator weights with the BoD model. The BoD model is a comprehensive indicator evaluation method, developed from the data envelopment analysis (DEA) model [46]. In order to avoid subjectivity of the evaluation and to ensure a scientific evaluation process, this paper integrates the BoD model and the less favorable BoD model with reference to the geometric composite index construction method of Pim Verbunt [47]. The two BoD models are established to derive $\xi_{i j}^{+}$and $\xi_{i j}^{-}$, respectively, to calculate the weight $\xi_{i j}$ in Formula (1), where $\xi_{i j}^{+}$is the optimistic weight of indicator $j$ in sample $i$, and $\xi_{i j}^{-}$is the pessimistic weight of indicator $j$ in sample $i$.

The optimistic BoD-weighting model:

$$
\begin{gathered}
\max \sum_{j=1}^{4} \xi_{i j}^{+} S I_{i j} \\
\text { s.t. }\left\{\begin{array}{c}
\sum_{j=1}^{4} \xi_{i j}^{+}=1 \\
\xi_{r}<\frac{\xi_{i j}^{+} S I_{i j}}{\sum_{j=1}^{4} \xi_{i j}^{+} S I_{i j}}<U_{r} \\
\xi_{i j}^{+} \geq 0
\end{array}\right.
\end{gathered}
$$

The pessimistic BoD-weighting model: 


$$
\begin{gathered}
\min \sum_{j=1}^{4} \xi_{i j}^{-} S I_{i j} \\
\text { s.t. }\left\{\begin{array}{c}
\sum_{j=1}^{4} \xi_{i j}^{-}=1 \\
\xi_{r}<\frac{\xi_{i j}^{-} S I_{i j}}{\sum_{j=1}^{4} \xi_{i j}^{-} S I_{i j}}<U_{r} \\
\xi_{i j}^{-} \geq 0
\end{array}\right.
\end{gathered}
$$

where $L_{r}$ is the lower limit of index or indicator weight, and $U_{r}$ is the upper limit of the index or indicator weight. In order to ensure the rationality of weight distribution and to avoid unrealistic results, this paper set $L_{r}=2 \%$ and $U_{r}=35 \%$ [48]. $S I_{i j}$ is solved by Equation (2). $\omega_{i j k}$ also uses two BoD models to calculate $\omega_{i j k}^{+}$and $\omega_{i j k}^{-}$, then $A S I_{i}$ and $S I_{i j}$ can be calculated according to the following formula:

$$
\begin{gathered}
A S I_{i}=\alpha A S I_{i}^{+}+(1-\alpha) A S I_{i}^{-} \\
S I_{i j}=\alpha S I_{i j}^{+}+(1-\alpha) S I_{i j}^{-}
\end{gathered}
$$

where $S I_{i j}^{+}$and $S I_{i j}^{-}$are calculated by $\omega_{i j k}^{+}$and $\omega_{i j k^{\prime}}^{-}$, respectively. $A S I_{i}^{+}$and $A S I_{i}^{-}$are calculated by $\xi_{i j}^{+}$ and $\xi_{i j}^{-} . \alpha$ is the adjustment parameter. In general, to strike a balance between the best and worst results, take 0.5 [41].

\section{Numerical Case Study}

This paper selects Guangzhou Baiyun International Airport (CAN) as a case study. CAN is the third largest hub airport in China, and it is an important link for sustainable development in Guangzhou, the Pearl River Delta region, and the country. Taking the development situation of the past 10 years (2008-2017) as a data resource, the above-mentioned AS evaluation methods and procedures are used to evaluate and analyze AS of CAN.

\subsection{Data Resource}

This paper gathers data of statistical AS indicators of CAN and calculates the other indicators through analysis and models. The statistical data sources are from the annual report of the airport [49], the airport service evaluation report issued by the Civil Aviation Passenger Service Evaluation [50,51], the Civil Aviation Administration website, and the flight operation efficiency report [52]. The calculation models include The AMS/EPA (American Meteorological Society/Environmental Protection Agency) Regulatory Model (AERMOD) model, which is used to calculate the concentration of pollutants around the airport; ICAO DOC 9911, which is used to calculate noise distribution around the airport; and the input-output model, which is used to calculate direct and indirect economic benefits.

\subsection{Indicator}

\subsubsection{Indicators Processing}

In order to make the indicators have the same magnitude, the value of indicators was normalized. The 54 normalized indicators of CAN from 2008 to 2017 are shown in Figure 2. 


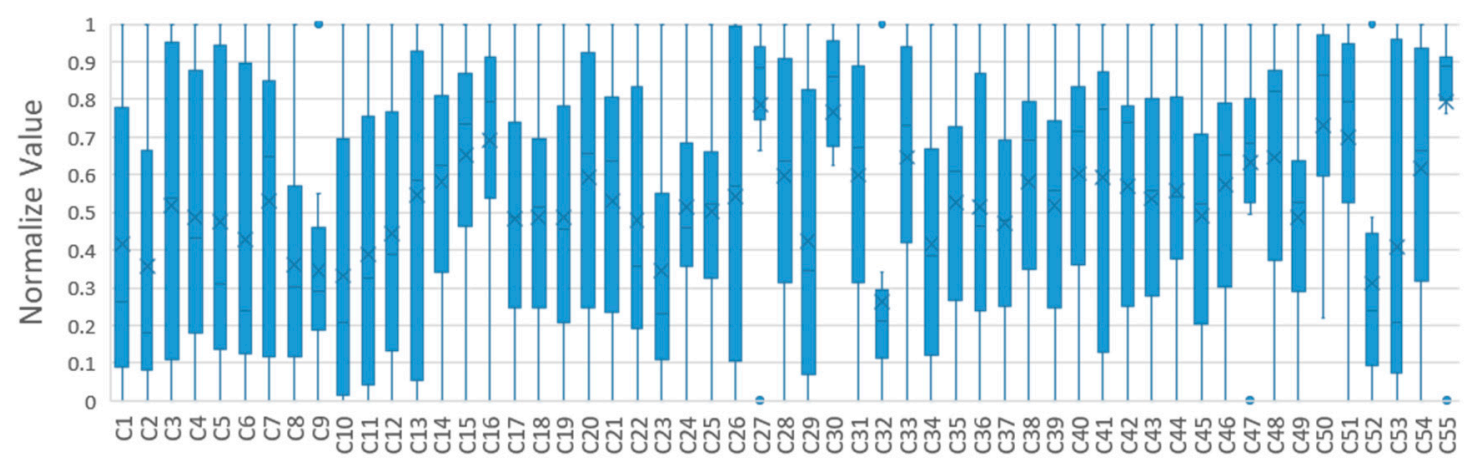

Indicators

Figure 2. Normalized AS indicators of CAN from 2008 2017.

Then, the indicators of each dimension needed to be screened. Firstly, the Spearman and Kendall correlation coefficient matrices of each indicator were constructed, and the confidence level of independence indicator was set to $5 \%$. Secondly, the non-parametric Bayesian discrimination was performed for the two indicator screening schemes, and then the independent indicator screening scheme was selected according to the discrimination accuracy. Thirdly, CGVM, PCA, and FCFA were used to screen representative indicators, and non-parametric shells were used for each indicator screening method. Finally, the representative indicator screening scheme was selected according to the non-parametric Bayesian discrimination accuracy. The non-parametric Bayesian discriminant accuracy of different indicator screening methods for each dimension is shown in Table 3.

Table 3. Non-parametric Bayesian discrimination accuracy.

\begin{tabular}{ccccccccc}
\hline \multirow{2}{*}{ Dimension } & \multicolumn{3}{c}{ Independence } & \multicolumn{3}{c}{ Representativeness } & Selected Screening \\
& before & Spearman & Kendall & before & CGVM & PCA & FCFA & Methods \\
\hline Economic (B1) & 0.405 & 0.78 & 0.76 & 0.78 & 0.77 & 0.88 & 0.77 & Spearman and PCA \\
Environmental (B2) & 0.318 & 0.39 & 0.61 & 0.61 & 0.73 & 0.84 & 0.82 & Kendall and PCA \\
Social (B3) & 0.38 & 0.63 & 0.68 & 0.68 & 0.65 & 0.72 & 0.79 & Kendall and FCFA \\
Operational (B4) & 0.25 & 0.55 & 0.69 & 0.69 & 0.71 & 0.79 & 0.85 & Kendall and FCFA \\
\hline
\end{tabular}

The selected screening scheme was as follows. Spearman and PCA were used to select seven indicators for independence and representativeness of the economic dimension, respectively. Kendall and PCA were used to select six indicators for independence and representativeness of the environmental dimension, respectively. Kendall and FCFA were used to select four indicators for independence and representativeness of the social dimension, respectively. Kendall and FCFA were used to select eight indicators for independence and representativeness of the operational dimension, respectively. These 25 indicators constitute the AS evaluation indicator system of CAN, as shown in Table 4.

Table 4. Evaluation indicator system of AS.

\begin{tabular}{ccc}
\hline Target & Dimension & Indicators \\
\hline & B1 & C2, C4, C5, C8, C13, C15, C16 \\
Airport sustainability & B2 & C22, C24, C27, C28, C29, C30 \\
& B3 & C 33, C35, C37, C38 \\
& B4 & C40, C43, C44, C46, C47, C49, C50, C51 \\
\hline
\end{tabular}

\subsubsection{Indicator Weighting}

The BoD model in Section 3.3 was used to determine the pessimistic indicator weight (PW) and optimistic indicator weight (OW) for each indicator. The results are shown in Figure 3. 


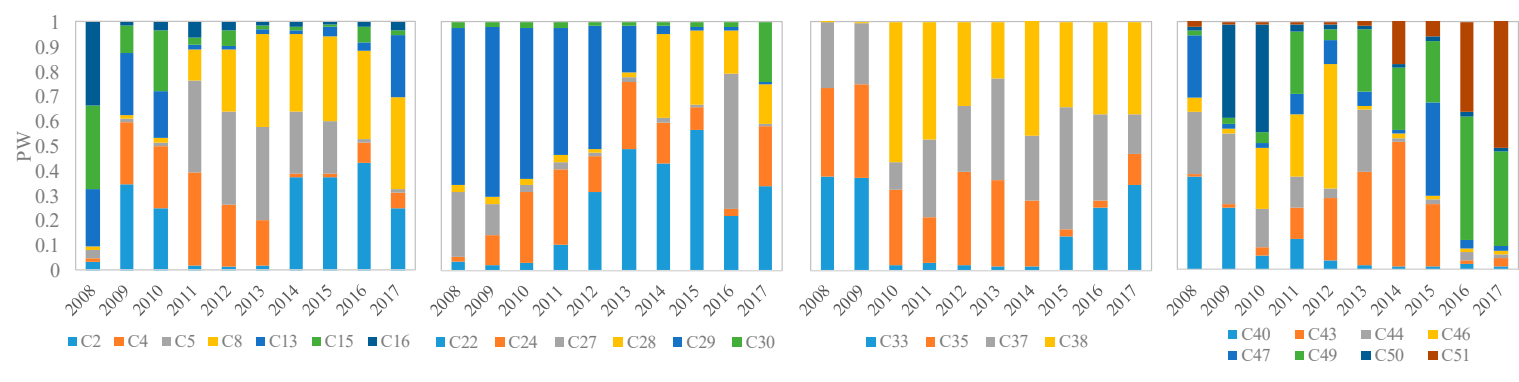
(a) Economic (PW)
(b) Environmental (PW)
(c) Social (PW)
(d) Operational (PW)

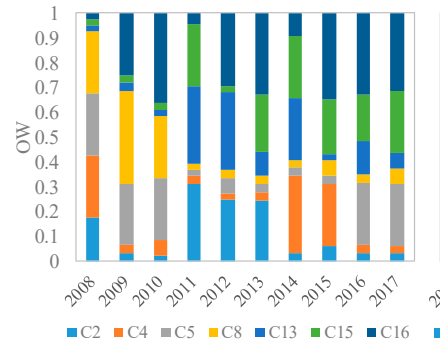

(e) Economic (OW)

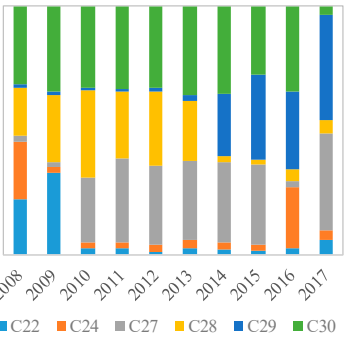

(f) Environmental (OW)

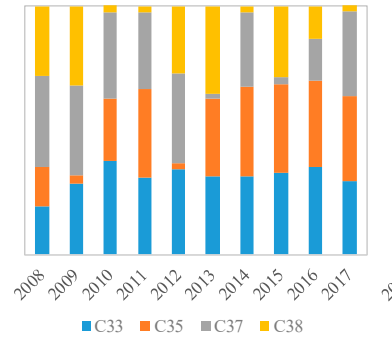

(g) Social (OW)

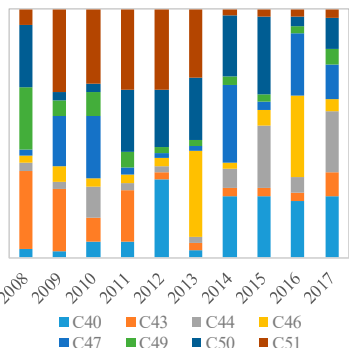

(h) Operational (OW)

Figure 3. The weight of each indicator.

\subsubsection{Determination of Standard Value}

The standard value of the indicator $g_{i}(d)$ usually takes the maximum value, which is the 100th percentile of the sample, but this determination method of the standard value has not been tested and verified. This paper determines the reasonable percentile value of the evaluation indicator by analyzing the standard deviation of the synthetic ASI under each percentile.

It can be seen from Table 5 that the deviation of the economic, environmental, and operational ASI is minimal at median (50th percentile), and the deviation of the social ASI is minimal at the 60th percentile, but the difference from the median is only 0.002 . Therefore, in order to unify the calculation method, this paper uses the median as the standard value to calculate the economic, environmental, social, and operational ASI, and d is set as equal to $50 \%$ in Formula (3).

Table 5. Standard deviation of the airport sustainability index (ASI) by percentile.

\begin{tabular}{cccccccccc}
\hline Percentile & $\mathbf{1 0}$ & $\mathbf{2 0}$ & $\mathbf{3 0}$ & $\mathbf{4 0}$ & $\mathbf{5 0}$ & $\mathbf{6 0}$ & $\mathbf{7 0}$ & $\mathbf{8 0}$ & $\mathbf{9 0}$ \\
\hline Economic (B1) & 0.547 & 0.490 & 0.457 & 0.328 & 0.210 & 0.585 & 0.616 & 0.624 & 0.631 \\
Environmental (B2) & 0.189 & 0.138 & 0.126 & 0.115 & 0.093 & 0.096 & 0.104 & 0.098 & 0.102 \\
Social (B3) & 0.436 & 0.49 & 0.214 & 0.201 & 0.195 & 0.193 & 0.546 & 0.436 & 0.49 \\
Operational (B4) & 0.051 & 0.044 & 0.041 & 0.048 & 0.04 & 0.055 & 0.064 & 0.051 & 0.044 \\
\hline
\end{tabular}

\subsection{ASI}

According to the normalized indicator value, indicator weight, and standard value, we used Formula (2) to calculate the economic, environmental, social, and operational ASI of CAN from 2008 to 2017. The comparison of each ASI and nominalized indicator is shown in Figure 4. 


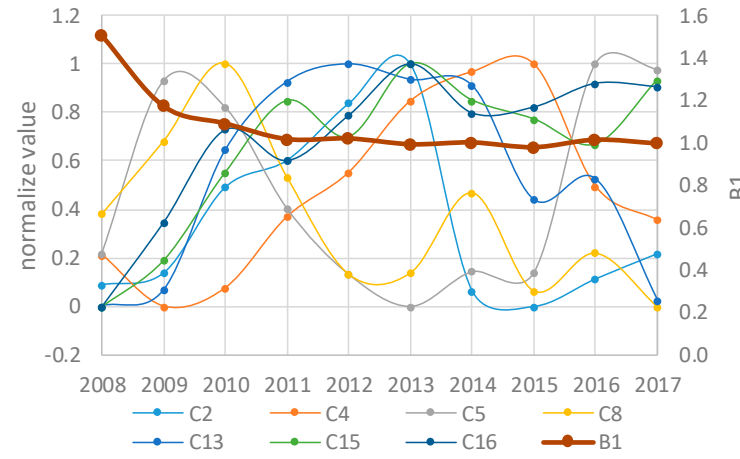

(a) Economic

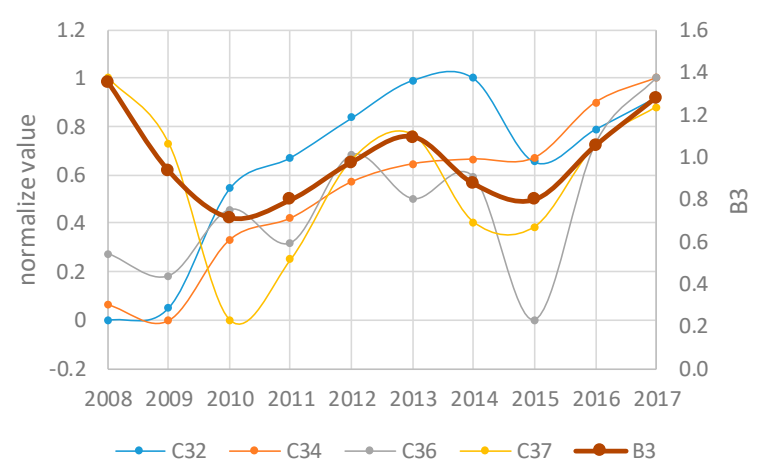

(c) Social

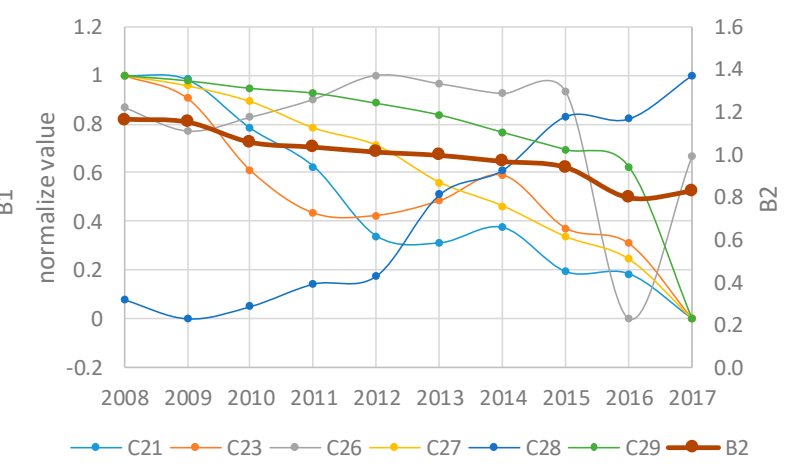

(b) Environmental

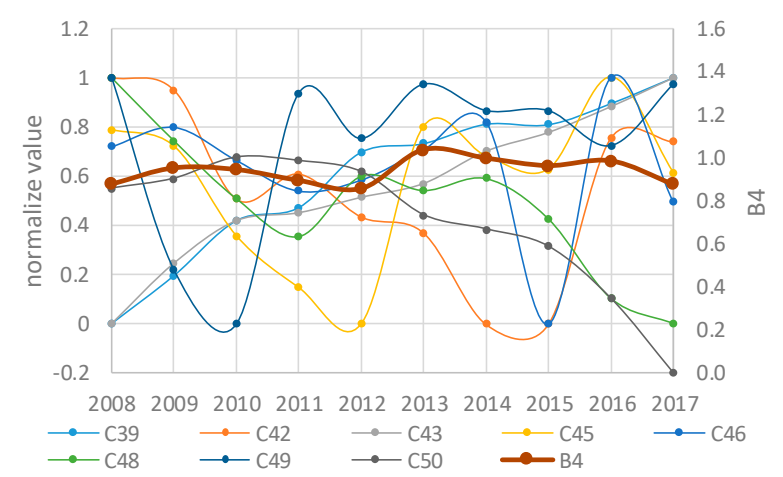

(d) Operational

Figure 4. Normalized indicators and ASI of each dimension.

In the economic dimension, $\mathrm{C} 13, \mathrm{C} 15$, and $\mathrm{C} 16$ are negative indicators and continue to grow while the remaining positive indicators fluctuate. These indicators eventually lead to a downward trend in the economic ASI. The environmental dimensional indicators are all negative indicators except $\mathrm{C} 28$, and the normalized value decreases with the increase of indicator value. In recent years, the environmental impact of the airport has become heavier, which is in line with the downward trend in the environmental ASI. The evaluation indicators in the social and operational dimensions fluctuate up and down; therefore, the social and operational ASI does not show a continuous upward and downward trend, and it is also a volatile change.

According to Formula (9), the pessimistic weight and optimistic weight of each dimension and ASI are shown in Table 6.

Table 6. The weight of each dimension and the ASI.

\begin{tabular}{cccccccccccc}
\hline \multicolumn{2}{c}{ Year } & $\mathbf{2 0 0 8}$ & $\mathbf{2 0 0 9}$ & $\mathbf{2 0 1 0}$ & $\mathbf{2 0 1 1}$ & $\mathbf{2 0 1 2}$ & $\mathbf{2 0 1 3}$ & $\mathbf{2 0 1 4}$ & $\mathbf{2 0 1 5}$ & $\mathbf{2 0 1 6}$ & $\mathbf{2 0 1 7}$ \\
\hline B1 & PW & 0.05 & 0.34 & 0.33 & 0.26 & 0.27 & 0.6 & 0.43 & 0.43 & 0.38 & 0.5 \\
& OW & 0.32 & 0.31 & 0.27 & 0.38 & 0.25 & 0.13 & 0.03 & 0.03 & 0.39 & 0.03 \\
B2 & PW & 0.08 & 0.02 & 0.02 & 0.02 & 0.02 & 0.28 & 0.25 & 0.2 & 0.46 & 0.35 \\
& OW & 0.34 & 0.33 & 0.25 & 0.33 & 0.38 & 0.25 & 0.28 & 0.33 & 0.03 & 0.33 \\
B3 & PW & 0.07 & 0.46 & 0.48 & 0.44 & 0.1 & 0.05 & 0.31 & 0.36 & 0.15 & 0.01 \\
& OW & 0.31 & 0.03 & 0.13 & 0.03 & 0.34 & 0.31 & 0.38 & 0.32 & 0.25 & 0.33 \\
B4 & PW & 0.81 & 0.19 & 0.17 & 0.3 & 0.61 & 0.07 & 0.01 & 0.02 & 0.02 & 0.14 \\
& OW & 0.03 & 0.34 & 0.36 & 0.27 & 0.03 & 0.31 & 0.32 & 0.32 & 0.33 & 0.31 \\
\multicolumn{2}{c}{ ASI } & 1.18 & 1.09 & 0.94 & 0.97 & 1.01 & 1.02 & 0.94 & 0.9 & 0.94 & 0.94 \\
\hline
\end{tabular}


If other determination methods of the indicator system weight are adopted, such as the entropy weight method (EWM) and principal component analysis method (PCA), the corresponding ASI evaluation results are shown in Table 7.

Table 7. The comparison of different weight determination methods.

\begin{tabular}{ccccccccccc}
\hline $\begin{array}{c}\text { Year } \\
\text { Method }\end{array}$ & \multicolumn{2}{c}{ 2008 } & \multicolumn{2}{c}{ 2009 } & \multicolumn{2}{c}{ 2010 } & \multicolumn{2}{c}{ 2011 } & \multicolumn{2}{c}{ 2012 } \\
EWM & PCA & EWM & PCA & EWM & PCA & EWM & PCA & EWM & PCA \\
\hline B1 & 1.16 & 0.02 & 1.18 & 0.22 & 1.11 & 0.92 & 1.05 & 1.40 & 1.06 & 1.70 \\
B2 & 1.24 & 1.03 & 1.18 & 1.00 & 1.11 & 0.86 & 1.07 & 0.73 & 1.02 & 0.63 \\
B3 & 1.64 & 0.14 & 1.25 & 0.10 & 1.01 & 0.25 & 1.02 & 0.29 & 0.97 & 0.45 \\
B4 & 0.92 & -0.39 & 0.92 & -0.35 & 0.93 & -0.27 & 0.93 & 0.04 & 0.98 & 0.02 \\
ASI & 1.51 & -0.67 & 1.23 & -0.65 & 1.03 & -0.16 & 1.03 & 0.21 & 0.98 & 0.55 \\
\hline Year & $\mathbf{2 0 1 3}$ & \multicolumn{2}{c}{$\mathbf{2 0 1 4}$} & $\mathbf{2 0 1 5}$ & $\mathbf{2 0 1 6}$ & $\mathbf{2 0 1 7}$ \\
Method & EWM & PCA & EWM & PCA & EWM & PCA & EWM & PCA & EWM & PCA \\
\hline B1 & 1.06 & 2.09 & 0.99 & 1.49 & 0.99 & 1.26 & 1.03 & 1.03 & 1.03 & 0.93 \\
B2 & 1.00 & 0.48 & 0.98 & 0.45 & 0.93 & 0.24 & 0.82 & 0.07 & 0.75 & -0.20 \\
B3 & 1.05 & 0.47 & 0.98 & 0.46 & 0.72 & 0.29 & 0.68 & 0.52 & 0.64 & 0.62 \\
B4 & 0.98 & 0.57 & 0.98 & 0.66 & 0.98 & 0.77 & 0.99 & 1.13 & 0.99 & 1.39 \\
ASI & 1.04 & 0.99 & 0.99 & 0.90 & 0.77 & 0.77 & 0.73 & 1.29 & 0.68 & 1.68 \\
\hline
\end{tabular}

Comparing the EWM, PCA, and BoD, the standard deviation of the PCA result is 0.6, which is obviously higher than 0.25 of EWM and 0.16 of BoD. In addition, the variation coefficient of the EWM's weight distribution is 0.379 , but PW and OW of BoD are 1.006 and 0.847 , which are significantly better than EWM. The BoD model can flexibly adjust the weight coefficient according to the actual airport data collected, which can better reflect the dynamic development process of the airport and the characteristics of sustainable development of the airport. The comprehensive evaluation results of the ASI change smoothly, which is consistent with the long-term stability of the airport's sustainable development strategy.

The ASI of CAN has a downward trend during 2008-2017, as shown in Figure 5, and it is a wave-like decline. By analyzing the variety of the ASI in each dimension, the change of ASI is mainly due to the economic and environmental ASI of CAN showing a downward trend in this decade. In terms of the economic ASI, the C2 indicator performed poorly among all indicators. The performance of C2 from 2013 to 2017 is worse than that from 2008 to 2012, indicating that CAN needs to pay attention to the development of its non-aeronautical business to promote economic sustainability. In addition to the C29 indicator showing an upward trend, other environmental indicators are showing a downward trend, indicating that CAN has to manage its pollutant emissions. The social and operational ASI undulate, and there is no continuous growth in all dimensions of the AS, which has caused the ASI of CAN to fluctuate up and down without forming stable growth momentum. In terms of social ASI, the performance of the C38 indicator fluctuated greatly, so C38 needs to be emphasized. When it comes to the operational ASI, the overall performance of each indicator fluctuated greatly, and there was no obvious development trend. Among them, the indicators that need to be paid attention to are C49 and C50, which have declined since 2014. This paper evaluates CAN's ASI from four dimensions and comprehensively considers the operational characteristics of CAN and the impact caused by economic development. According to the law of change, if the economic and environmental ASI is strengthened, it can promote the ASI of CAN. 


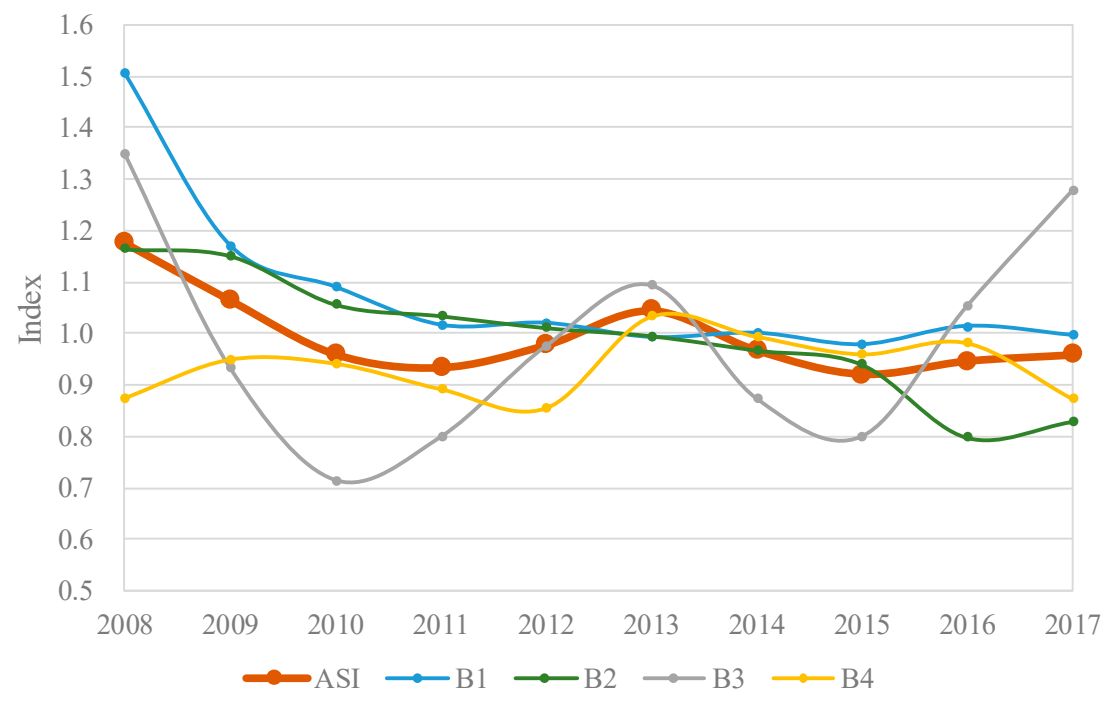

Figure 5. ASI of each dimension.

\subsection{Discussion}

Promoting AS has become a key issue that attracts much attention. Taking the development of the transportation industry as a reference, this paper analyzes the impact of external factors on AS from the four aspects of the sustainable development needs, the development background of civil aviation, the economic environment, and competitiveness [53]. The main influencing factors are shown in Table 8.

Table 8. The influencing factors of AS.

\begin{tabular}{cc}
\hline Aspect & Influencing Factors \\
\hline Sustainable development demand & F1: The total population of Guangzhou \\
F2: Government subsidies
\end{tabular}

For the extraction methods of important influencing factors, there are currently parallel genetic algorithms and random stepwise integration, bagging, etc. Due to the small sample size and large number of dimensions, this study used the parallel genetic algorithm (PGA) to analyze the influencing factors. The parallel genetic algorithm (PGA) was used to analyze the relationship between the actual data from 2008 to 2017 and the AS. The impact of various influencing factors on the AS is shown in Figure 6.

The size of the circle in Figure 6 indicates the degree of impact. It can be seen that F1 and F4 are the two most influential factors, indicating that the sustainability demand of Guangzhou and the national development background of civil aviation in the past decade have a relatively large impact on the ASI. The reason that F1 hinders the development of the airport may be that CAN has not yet effectively utilized the economic benefits brought by the increased passenger volume, and the increased passenger volume has a worse impact on the airport environment; therefore, the ASI failed to grow with F1. 


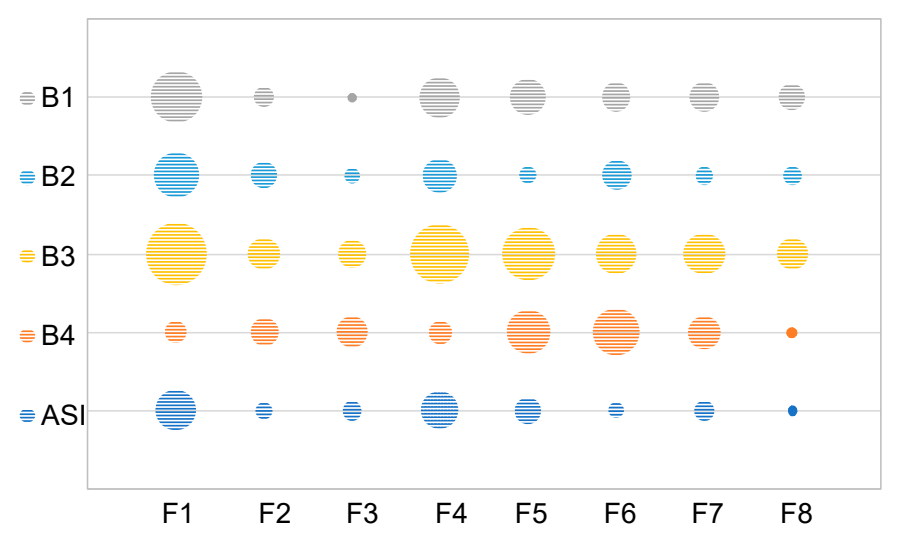

Figure 6. The influencing factors of each ASI.

F4 promotes the development of the airport, while F6 does not have a significant impact on the ASI, which indicates that CAN has more mileage on extra-provincial routes, and the extra-provincial route mileage has a greater impact on the ASI of CAN.

In this paper, the linear regression model method is used to analyze the influence mechanism of the airport's sustainable development ability based on the obtained airport sustainable development comprehensive index and influencing factors. The Tobit regression is one of the linear regression models. It is mainly used to explore the relationship between unobservable variables and observable independent variables. Because the airport sustainable development index has upper and lower limits, the Tobit regression is more suitable for regression analysis of such independent variables. Tobit regression was performed on ASI and two influencing factors using Stata 16.0 software. The regression results are shown in Table 9.

Table 9. The regression results of Tobit.

\begin{tabular}{ccccc}
\hline Variable & Coefficient & Standard Deviation & T Test & $P>|t|$ \\
\hline F1 & -0.00154 & 0.000277 & -5.55 & 0.001 \\
F4 & 0.000548 & 0.000155 & 3.53 & 0.008 \\
_cons & 2.750668 & 0.298724 & 9.21 & 0 \\
\hline
\end{tabular}

The regression model of ASI can be expressed as:

$$
A S I=-0.00154 \cdot F 1+0.000548 \cdot F 4+2.750668
$$

This regression model is based on the relationship between historical ASI and influencing factors. After extracting important influencing factors through PGA, it can be seen from Table 9 that F4 promotes the development of the airport, while the impact of F1 is the opposite. It shows that CAN could use the development of the civil aviation industry in China effectively and strive to take advantage of policy advantages to transform F4 into a favorable factor for ASI. However, at the same time, it will bring a more serious impact on the airport environment; the more use of F1 means a greater number of people affected by the environment, which will restrict airport sustainability.

The ASI can be a predicted value as long as F1 and F4 are known. Figure 7 is a comparison chart between the calculated value of the comprehensive indicator evaluation method (ASI) and the calculated value of the regression model (ASI_Tobit). It can be seen in the figure that the change trend of ASI_Tobit and the ASI is consistent, which is a volatile decline, and ASI_Tobit shows a continuous downward trend after 2014. According to the regression function, the ASI of 2018 is 0.915 . That is, if CAN is in accordance with the current mode of operation and development, the ASI may continue to decline in the short term. 


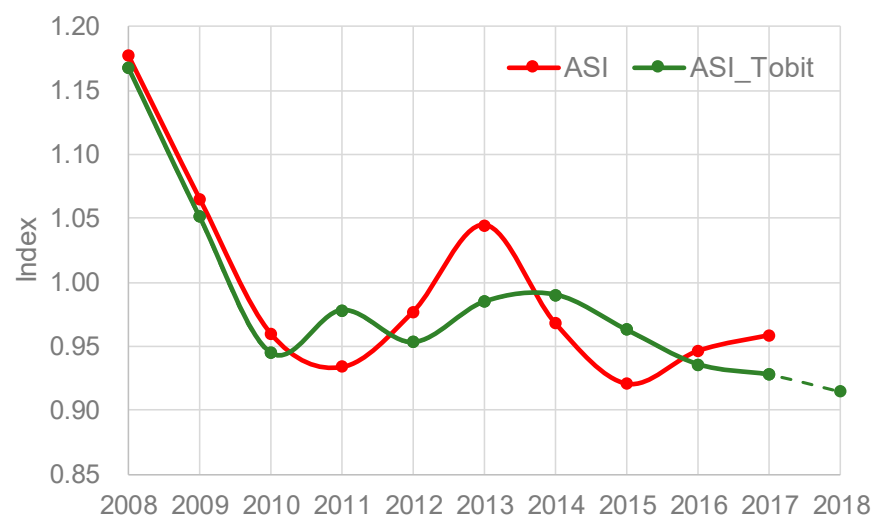

Figure 7. Comparison chart of ASI and ASI_Tobit.

\section{Conclusions}

Although the concept of sustainable development has achieved certain results in various fields, for the sustainable development of the airport, there has not yet been formed a unified sustainable development theory and evaluation method. In order to enable the theory of AS to be applied in practice, this article mainly focuses on the evaluation of AS. The main research results are as follows:

1. Concept and evaluation framework: Based on the existing concepts of sustainable development and airport sustainable development, and combined with the development characteristics of China's airports, the definition, connotation, and dimensions of China's AS are put forward, and the evaluation process is established according to the indicator evaluation method.

2. Indicators and indicator systems: The non-parametric Bayesian model was used to select the best indicator independence and representative screening methods, and an indicator system of AS was established that includes four criteria layers: economy, environment, society, and operation.

3. Comprehensive evaluation index: The improved BoD model was used to determine the weight of the index and indicator, and the comprehensive ASI was obtained by combining weights with indicators through an improved index construction method (WP).

4. Impact and prediction: The influencing factors and mechanism of the AS are discussed. The Tobit model was used to analyze and predict the ASI of CAN combining the actual historic data of CAN. The sustainable development performance of CAN in 2018 declined compared to 2017.

This paper uses CAN as a case study to verify the feasibility of the AS evaluation method and process; other airports can also use this method to assess their AS. Although different airports have different sustainable development modes, the evaluation method proposed in this paper is a set of packaged methods. When evaluating any airport, we can use this evaluation method to obtain the evaluation and prediction results based on the data of this airport. Obviously, the evaluation results and influential factors of each airport will be different. Further research on the influencing factors and characteristics of sustainable development modes can be carried out to promote AS.

Author Contributions: Data curation, J.W.; Funding acquisition, Y.T.; Methodology, L.W.; Software, C.X.; Writing-review \& editing, Q.P. All authors have read and agreed to the published version of the manuscript.

Funding: This research was funded by the National Natural Science Foundation of China, grant number 61671237 and the National Natural Science Foundation of China, grant number U1933119 and the innovation training program, grant number 2019CX00703).

Conflicts of Interest: The authors declare no conflicts of interest.

\section{References}

1. Brundtland Commission. Our Common Future; Oxford University Press: New York, NY, USA, 1987.

2. Stephenson, J.; Spector, S.; Hopkins, D.; McCarthy, A. Deep interventions for a sustainable transport future. J. Transp. Res. Part D Transp. Environ. 2017, 61, 356-372. [CrossRef] 
3. Mrazova, M. Sustainable development-The key for green aviation. INCAS Bull. 2014, 6, 109-122.

4. McManners, J.P. Developing policy integrating sustainability: A case study into aviation. Environ. Sci. Pol. 2016, 57, 86-92. [CrossRef]

5. Baxter, G.; Srisaeng, P.; Wild, G. Sustainable Airport Energy Management: The Case of Kansai International Airport. Int. J. Traffic Transp. Eng. 2018, 8, 334-358.

6. Baxter, G.; Srisaeng, P.; Wild, G. An assessment of airport sustainability, part 1-waste management at Copenhagen Airport. Resources 2019, 7, 21. [CrossRef]

7. Buckwalter Berkooz, C. Sustainable Airports Take Flight. Planning 2015, 81, 10.

8. San Diego International Airport. Airport Development Plan Making Strides. Available online: http: //sustain.san.org/operational/ (accessed on 3 June 2019).

9. San Francisco International Airport. San Francisco International Airport 2014 Sustainability Report. Available online: https://media.flysfo.com/media/sfo/community-environment/sfo-2014-sustainability-report.pdf (accessed on 15 May 2019).

10. Sustainable Airport Master Plan. Available online: https://sampntpenvironmentalreview.org/ (accessed on 13 May 2019).

11. Heathrow Airport. Detailed Review of Sustainability Progress in 2017. Available online: https://www.heathrow.com/content/dam/heathrow/web/common/documents/company/heathrow-

2-0-sustainability/futher-reading/detailed-review-of-sustainability-progress-2017.pdf (accessed on 12 October 2018).

12. Sustainable Airport Solutions. Continuous Descent Approach Groningen Airport Eelde-The Netherlands; Groningen Airport Eelde: Eelde, The Netherlands, 2012.

13. Smart Island Report 2016. Available online: http://www.kansai-airports.co.jp/en/efforts/environment/kix/ smart-island/file/smart_rprt16.pdf (accessed on 17 June 2019).

14. Airport Authority Hong Kong. Sustainability Report. Available online: http://www.hongkongairport.com/ iwov-resources/html/sustainability_report/chi/SR1718/index.html (accessed on 17 June 2019).

15. Sarkar, A.N. Evolving Green Aviation Transport System: A Hoilistic Approah to Sustainable Green Market Development. Am. J. Clim. Chang. 2012, 1, 17.

16. McManners, $\mathrm{P}$. The action research case study approach: A methodology for complex challenges such as sustainability in aviation. Action Res. 2016, 14, 201-216. [CrossRef]

17. Payan-Sanchez, B.; Plaza-Ubeda, J.A.; Pérez-Valls, M.; Carmona-Moreno, A. Social Embeddedness for Sustainability in the Aviation Sector. Corp. Soc. Responsib. Environ. Manag. 2017, 25, 537-553. [CrossRef]

18. Monsalud, A.; Ho, D.; Rakas, J. Greenhouse gas emissions mitigation strategies within the airport sustainability evaluation process. Sustain. Cities Soc. 2015, 14, 414-424. [CrossRef]

19. Mahmoudi, R.; Shetab-Boushehri, S.N.; Hejazi, S.R.; Emrouznejad, A. Determining the relative importance of sustainability evaluation criteria of urban transportation network. Sustain. Cities Soc. 2019, 47, 101493. [CrossRef]

20. Uysal, M.P.; Sogut, M.Z. An integrated research for architecture-based energy management in sustainable airports. Energy 2017, 140, 1387-1397. [CrossRef]

21. Somerville, A.; Baxter, G.S.; Richardson, S.; Wild, G. Sustainable water management at major Australian regional airports: The case of Mildura Airport. Aviation 2015, 19, 83-89. [CrossRef]

22. Greg, W.; Helen, F.; Ali, J. Sustainable Runway Pavement Rehabilitation: A case study of an Australian Airport. J. Clean. Prod. 2018, 204, 380-389.

23. Setiawan, M.I.; Surjokusumo, S.; Ma'some, D.M.; Johan, J.; Hasyim, C.; Kurniasih, N.; Sukoco, A.; Dhaniarti, I.; Suyono, J.; Sudapet, I.N.; et al. Business Centre Development Model of Airport Area in Supporting Airport Sustainability in Indonesia. In Journal of Physics: Conference Series, Proceedings of the 2nd International Conference on Mathematics, Science, Technology, Education, and their Applications (2nd ICMSTEA), Makassar, Indonesia, 3-4 October 2016; IOP Publishing: Bristol, UK, 2018; Volume 954.

24. Janic, M. An Application of the Methodology for Assessment of the Sustainability of the Air Transport System. J. Air Transp. 2004, 9, 40-82.

25. Fasone, V.; Maggiore, P. Airport development and sustainability: A case of multi-airport system in Italy. Int. J. Sustain. Aviat. 2014, 1, 13-24. [CrossRef]

26. Kılkış, Ş.; Kılkış, Ş. Benchmarking airports based on a sustainability ranking index. J. Clin. Prod. 2016, 130, 248-259. [CrossRef] 
27. Postorino, M.N.; Mantecchini, L.; Paganelli, F. Green Airport Investments to Mitigate Externalities: Procedural and Technological Strategies. In Sustainable Entrepreneurship and Investments in the Green Economy; IGI Global: Hershey, PA, USA, 2017; pp. 231-256.

28. Ming-Tsang, L.; Chao-Che, H.; Liou, J.J.H.; Lo, H.W. A hybrid MCDM and sustainability-balanced scorecard model to establish sustainable performance evaluation for international airports. J. Air Transp. Manag. 2018, 71,9-19. [CrossRef]

29. Olfata, L.; Amiri, M.; Soufi, J.B.; Pishdar, M. A dynamic network efficiency measurement of airports performance considering sustainable development concept: A fuzzy dynamic network-DEA approach. J. Air Transp. Manag. 2016, 57, 272-290. [CrossRef]

30. Airport Commission. Appraisal Framework; Airport Commission: London, UK, 2014.

31. Airport Cooperative Research Program (ACRP). Synthesis 10: Airport Sustainability Practices Explores Airport Sustainability Practices Across Environmental, Economic, and Social Issues; Airport Cooperative Research Program: Washington, DC, USA, 2008.

32. SAGA. Sustainable Aviation Resource Guide: Planning, Implementing and Maintaining a Sustainability Program at Airports; Sustainable Aviation Guidance Alliance: Washington, DC, USA, 2010.

33. Federal Aviation Administration. Airport Sustainability; Federal Aviation Administration: Washington, DC, USA, 2019.

34. Aerospace Systems International. Environment; Aerospace Systems International: Wichita, KS, USA, 2019.

35. Oto, N.; Cobanoglu, N.; Geray, C. Education for Sustainable Airports. Procedia Soc. Behav. Sci. 2012, 47, 1164-1173. [CrossRef]

36. China Civil Aviation Administration. The 13th Five-Year Plan for the Development of China's Civil Aviation; China Civil Aviation Administration: Beijing, China, 2016.

37. Welford, R. Environmental Strategy and Sustainable Development: The Corporate Challenge for the Twenty-First Century; Routledge: London, UK, 1995.

38. Bartle, J.R. The Sustainable Development of U.S. Air Transportation: The Promise and Challenge of Institutional Reform. Public Works Manag. Policy 2006, 10, 214-224. [CrossRef]

39. Lutte, R.K.; Bartle, J.R. Sustainability in the Air: The Modernization of International Air Navigation. Public Works Manag. Policy 2017, 22, 322-334. [CrossRef]

40. International Air Transport Association. Airport Development; International Air Transport Association: Montreal, QC, Canada, 2019.

41. Zhou, P.; Ang, B.W.; Poh, K.L. Comparing aggregating methods for constructing the composite environmental index: An objective measure. Ecol. Econ. 2006, 59, 305-311. [CrossRef]

42. Global Reporting Initiative. Sustainability Reporting Guidelines E Airport Operators Sector Supplement; Global Reporting Initiative: Amsterdam, The Netherlands, 2011.

43. Ferrulli, P. Green Airport Design Evaluation (GrADE)-Methods and Tools Improving Infrastructure Planning. Transp. Res. Procedia 2016, 14, 3781-3790. [CrossRef]

44. Li, L.; Loo, B.P.Y. Impact analysis of airport infrastructure within a sustainability framework: Case studies on Hong Kong International Airport. Int. J. Sustain. Transp. 2016, 10, 781-793. [CrossRef]

45. Cheng, L. Research on Evaluation Index System of Green Airport Based on Full Life Cycle. Master's Thesis, Civil Aviation University of China, Tianjin, China, 2014.

46. Charnes, A.; Cooper, W.W.; Rhodes, E. Measuring the efficiency of decision making units. Eur. J. Op. Res. 1978, 2, 429-444. [CrossRef]

47. Verbunt, P.; Rogge, N. Geometric composite indicators with compromise Benefit-of-the-Doubt weights. Eur. J. Opt. Res. 2018, 264, 388-401. [CrossRef]

48. Cherchye, L.; Moesen, W.; Rogge, N.; Van Puyenbroek, T. An Introduction to 'Benefit of the Doubt', Composite Indicators. Soc. Indic. Res. 2007, 82, 111-145. [CrossRef]

49. Guangzhou Baiyun International Airport Co. Ltd. Annual Report; Guangzhou Baiyun International Airport Co. Ltd.: Guangzhou, China, 2008.

50. Civil Aviation Passenger Service Evaluation. Airport Service Evaluation Report; Civil Aviation Passenger Service Evaluation: Hefei, China, 2008.

51. China Civil Aviation Administration. Notification of Consumer Complaints in Air Transport; Civil Aviation Administration: Beijing, China, 2008. 
52. China Civil Aviation Administration. National Civil Aviation Flight Operation Efficiency Report; Civil Aviation Administration: Beijing, China, 2008.

53. Schuckmann, S.W.; Gnatzy, T.; Darkow, I.L.; von der Gracht, H.A. Analysis of factors influencing the development of transport infrastructure until the year 2030-A Delphi based scenario study. Technol. Forecast. Soc. Chang. 2012, 79, 1373-1387. [CrossRef] 